\title{
0 Gênero do Substantivo em Português: por que Flexão e por que Morfologia?
}

\section{Luiz Carlos de Assis Rocha}

Este trabalho é parte da dissertação $O$ Gênero do Substantivo em Português: uma Categoria Morfo-sintática, apresentada ao Curso de Pós-Graduação da Faculdade de Letras da UFMG, em março de 1982, para obtenção do grau de Mestre em Lingua Portuguesa.

Já dizia Mattoso Câmara que "a categoria gramatical de gênero é um dos traços flexionais menos satisfatoriamente descritos em nossas gramáticas". ${ }^{1}$ Confirmam as palavras do Mestre os desencontros que existem entre as gramáticas e os desencontros maiores ainda que se observam entre as gramáticas e os dados concretos da língua.

Para tentar resolver a questão do conceito de gênero gramatical e a sua caracterização no quadro geral da gramática portuguesa, fizemos uma pesquisa em um determinado "corpus"; escolhemos quatro tipos de texto. e extraímos, analisamos e classificamos 1.000 substantivos de cada um deles, perfazendo um total de 4.000 substantivos.

1. CĀMARA JR., J. Mattoso. «Considerações sobre o gênero em Porm tuguês». In: Dispersos. Rio de Janeiro, Fundação Getúlio Vargas, 1972, p. 115. 
Os textos são os seguintes:

a) Técnico - Horácio Rolim de FREITAS. Princípios de Morfologia. Rio de Janeiro, Presença, 1979.

b) De reportagem - Veja. São Paulo. Ed. Abril, n. 657, abr. 1981.

c) De memórias - Fernando GABEIRA. O que é isso, Companheiro: 22. ed., Rio de Janeiro, Codecri, 1980.

d) De ficção - Machado de ASSIS. Memórias Póstumas de Brás Cubas. São Paulo, Jackson, 1946.

Para classificar os substantivos, usamos determinados traços, que são apresentados no quadro abaixo ( $n^{\circ} 1$ ). Esses traços̃, que não coincidem "in totum" com os adotados pela gramática tradicional, estão expostos, com maior rigor, em nossa dissertação. Aqui, por motivos óbvios, não podemos descer a pormenores na explicação desses traços, bem como na apresentação de vários aspectos da dissertação. O certo é que, usando parte de um dos textos do "corpus" como amostra, o de Machado de Assis, chegamos ao quadro 1, transcrito na página 102.

A respeito desse quadro, podemos fazer os seguintes esclarecimentos:

1 - Os substantivos apresentam uma divisão básica inicial: os que não se referem a pessoas e que estão marcados, portanto, com o traço - sexuado; e os que se referem a pessoas e que carregam, portanto, o traço + sexuado.

Os substantivos de traço - sexuado apresentam, todos eles, o traço - flexão. Além disso, dividem-se em masculinos e femininos, pelo fato de admitirem os artigos $o$ ou $a$, respectivamente.

2 - Os substantivos de traço + sexuado dividem-se, inicialmente, em dois grupos, independentemente do gênero a que pertencem. 
1. GRUPO: amigos (duas vezes), fiéis, senhores, caracteres, viajante, leitor, pessoas, cegonhas.

Eis os contextos em que esses nomes aparecem:

". . e fui acompanhado ao cemitério por onze amigos." (p. 11) “... e fui acompanhado ao cemitério por onze amigos. Onze amigos!” (p. 11)

“... tão constante e tão triste que levou um daqueles fiéis da última hora a intercalar esta engenhosa idéia..." (p. 12)

"Vós, que o conhecestes, meus senhores, vós podeis dizer comigo..." (p. 12)

"... a natureza parece estar chorando a perda irreparável de um dos mais belos caracteres que têm honrado a humanidade." (p. 12)

"E a imaginação dela, como as cegonhas que um ilustre viajante viu desferirem o vôo desde o Ilisso às..." (p. 13)

"... é possível que o leitor me não creia, e todavia é verdade..." (p. 14)

"Viram-me ir umas nove ou dez pessoas..." (p. 12)

"E a imaginação dela, como as cegonhas que um ilustre viajante viu desferirem o vôo desde o Ilisso às..." (p. 13)

Apesar de serem masculinos ou femininos, esses nomes não estabelecem distinção quanto ao sexo dos seres a que se referem. São substantivos marcados com o traço - distinção.

Esses substantivos não apresentam flexão, nem em qualquer contexto (fiéis, caracteres, viajante, pessoas e cegonhas), nem no texto em estudo (amigos, senhores e leitor). Caracterizam-se também pelo fato de serem portadores do traço - flexão. 
QUADRO 1

\begin{tabular}{|c|c|c|c|c|c|c|c|}
\hline \multicolumn{2}{|c|}{ - SEXUA D O } & \multicolumn{6}{|c|}{$+S \mathbb{E} \times \mathbb{A D O}$} \\
\hline \multirow{2}{*}{\multicolumn{2}{|c|}{ 一 FLEXão }} & \multirow{2}{*}{\multicolumn{2}{|c|}{$\frac{\text { - DISTINGão }}{\text { - ELEXão }}$}} & \multicolumn{4}{|c|}{ ＋ DXSTINGão } \\
\hline & & & & \multicolumn{2}{|c|}{ 一 FLEXão } & \multicolumn{2}{|c|}{ + FLeXão } \\
\hline maseulino & feminino & masculino & feminino & masculino & feminino & masculino & feminino \\
\hline $\begin{array}{l}\text { óbito } \\
\text { tempo } \\
\text { principio } \\
\text { fim } \\
\text { lugar } \\
\text { nascimento } \\
\text { uso } \\
\text { nascimento } \\
\text { método } \\
\text { berco } \\
\text { escrito } \\
\text { intróito } \\
\text { cabo } \\
\text { livro } \\
\text { mess } \\
\text { agosto } \\
\text { etc. } \\
\end{array}$ & $\begin{array}{l}\text { memórias } \\
\text { morte } \\
\text { consideraçōes } \\
\text { campa } \\
\text { morte } \\
\text { diferença } \\
\text { horas } \\
\text { tarde } \\
\text { sexta-feira } \\
\text { chácara } \\
\text { cartas } \\
\text { chuvinha } \\
\text { hora } \\
\text { idéia } \\
\text { cova } \\
\text { natureza } \\
\text { etc. }\end{array}$ & $\begin{array}{l}\text { amigos } \\
\text { amigos } \\
\text { fiéis } \\
\text { senhores } \\
\text { caracteres } \\
\text { viajante } \\
\text { leitor }\end{array}$ & $\begin{array}{l}\text { pessoas } \\
\text { cegonhas }\end{array}$ & $\begin{array}{l}\text { lírio do vale } \\
\text { homens } \\
\text { amolador } \\
\text { correeiro }\end{array}$ & damas & $\begin{array}{l}\text { autor } \\
\text { autor } \\
\text { defunto } \\
\text { finado } \\
\text { amigo } \\
\text { moço } \\
\text { solteirão }\end{array}$ & $\begin{array}{l}\text { senhoras } \\
\text { irmã } \\
\text { filha } \\
\text { parentas } \\
\text { anônima } \\
\text { senhora } \\
\text { senhora }\end{array}$ \\
\hline
\end{tabular}


Consideramos amigos, senhores e leitor como substantivos destituídos de flexão, embora tal ponto de vista possa, a princípio, parecer estranho. E preciso, porém, observar que estamos apoiando nossas considerações em um determinado texto, em que o flexionamento dos citados vocábulos não pode ocorrer; por se tratar de substantivos de uso indefinido, quanto ao gênero. Como sabemos, os substantivos desse tipo, quando referentes a pessoas, estão sempre no masculino. A propósito dessa colocação, Pottier simboliza a questão, no espanhol, do seguinte modo: ${ }^{2}$

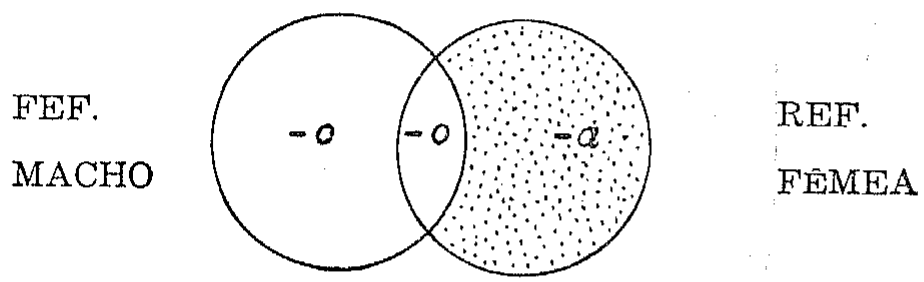

Aplicando ao português a simbolização de Pottier, verificamos que o gênero masculino (apresentado pela desinência - o) pode ser empregado para denotar não apenas seres do sexo masculino, mas também seres dos dois sexos, quando o uso é indefinido.

Ainda com relação a amigos, senhores e leitor, que assinalamos como sendo destituídos de flexão, é preciso, por uma questão de coerência, levar em consideração o seguinte raciocínio: se admitimos que os substantivos mencionados apresentam o traço - distinção, fatalmente também terão o traço - flexão, uma vez que a flexão de gênero denota sempre distinção de sexo.

2. GRUPO: autor (duas vezes), defunto, finado, amigo, moço, lírio do vale, solteirão, homens, amolador, correeiro, senhoras, irmã, filha, senhora (três vezes), anônima (duas vezes), parenta, parentas, damas.

2. POTTIER, Bernard. Gramática del Español. Madrid, Alcalá, 1970, p. 42. 
Esses nomes aparecem nos seguintes contextos:

"Obto do autor". (título do capítulo) (p. 11)

“...eu não sou propriamente um autor defundo, mas um defunto autor..." (p. 11)

“...eu não sou propriamente um autor defundo, mas um defunto autor..." (p. 11)

"... tudo isso é um sublime louvor ao nosso ilustre finado." (p. 12)

"Bom e fiel amigo!" (p. 12)

“. . foi assim que encaminhei para o 'undiscovered country' de Hamlet, sem as ânsias nem as dúvidas do moço príncipe..." (p. 12)

“...entre elas três senhoras, minha irmã Sabina, casada com o Cotrim, a filha - um lírio do vale - e..." (p. 12)

"Um solteirão, que expira aos sessenta e quatro anos, não parece que reúna em si todos os elementos de uma tragédia." (p. 13)

"Agora, quero morrer tranqüilamente, metodicamente, ouvindo os soluços das damas, as falas baixas dos homens..." (p. 13) “. . ouvindo os soluços das damas,... e o som estrídulo de uma navalha que um amolador está afiando lá fora..." (p. 13) “... o o som estrídulo de uma navalha que um amolador está afiando lá fora, à porta de um correeiro." (p. 13)

"Viram-me ir umas nove ou dez pessoas, entre elas três senhoras, minha irmã Sabina..." (p. 12)

“... entre elas três senhoras, minha irmã Sabina, casada com o Cotrim, a filha - um lírio do vale..." (p. 12)

"Tenham paciência! Daqui a pouco lhes direi quem era a terceira senhora." (p. 12)

"De pé, à cabeceira da cama... a triste senhora mal podia crer na minha extinção." (p. 13)

"... imaginação dessa senhora também voou sobre os destroços..." (p. 13) 
"Contentem-se de saber que essa anônima, ainda que não parenta..." (p. 12)

"E; dado que sim, o que menos convinha a essa anônima era aparentá-lo." (p. 13)

"Contentem-se de saber que essa anônima, ainda que não parenta..." (p. 12)

"Contentem-se de saber que essa anônima, ainda que não parenta, padeceu mais do que as parentes." (p. 12)

"Agora, quero morrer tranqüilamente, metodicamente, ouvindo os soluços das damas, as falas baixas dos homens..." (p. 13)

Os substantivos desse grupo apresentam o traço + distinçäo. Mas aqui podemos separar esses substantivos em dois subgrupos, com os seguintes traços característicos:

-flexão: lírio do vale, homens, amolador, correeiro, damas.

+ flexão: autor, defunto, finado, amigo, moço, solteirão, senhoras, irmã, filha, parentas, anônima, senhora.

Há duas observações a fazer a respeito de alguns nomes que apresentam o traço - flexão.

Lírio do vale denota um tipo de flor, como registram os nossos dicionários. No texto em estudo, aparece, porém, em linguagem metafórica, referindo-se à sobrinha do autor. Trata-se, é evidente, de um substantivo marcado pelo traço semântico + sexuado e pelo traço morfológico - flexão.

Amolador e correeiro estão entre aqueles nomes da Língua Portuguesa que apresentam os femininos amoladora e correeira, sob o ponto de vista do sistema. Sob o ponto de vista da norma, porém, no sentido em que Eugenio Coseriu empregou esse termo, apenas as formas masculinas são consagradas pelo uso. Isso se deve ao fato de que certas profissões são exercidas habitualmente só por homens ou só por mulheres. $\overline{\mathrm{E}}$ o caso de substantivos como pedreiro, carpinteiro, bombeiro, cerzideira, arrumadeira, em que um dos gêneros é exclusivo. Trata-se, é evidente, de um problema cultural, com repercussões no plano linguiústico. 
O quadro $\mathrm{n}^{\circ} 1$, há pouco transcrito, foi testado, primeiramente, em todo o texto de ficção. Verificada a sua funcionalidade, passou a servir de base para o recolhimento de dados nos quatro textos que constituem o "corpus" da pesquisa.

\section{GÊNERO E FLEXÃO}

Os dados obtidos com o levantamento feito nos quatro textos permitem-nos fazer algumas considerações a respeito do gênero e da flexão dos substantivos em Língua Portuguesa.

Segundo Mattoso Câmara, flexão é o "processo de 'flectir', isto é, fazer variar um vocábulo para nele expressar dadas categorias gramaticais". ${ }^{3}$

Nos exemplos abaixo, estamos diante de substantivos que recebem flexão, ou seja, nota-se claramente o "processo de flectir", os vocábulos "variam" para indicar a diferença de gênero:

O aluno estuda as lições de Matemática.

A aluna estuda as lições de Matemática.

O lobo protege seus filhotes.

A $l o b a$ protege seus filhotes.

A tradição gramatical portuguesa, baseada em exemplos desse tipo, apresenta os substantivos como tendo flexão de gênero. $\overline{\mathrm{E}} \mathrm{o}$ que estabelecem, com raras exceções, as nossas gramáticas.

Para comprovar o que estamos afirmando, fizemos um levantamento da questão em algumas de nossas gramáticas e dividimos as posições dos autores em dois grupos.

No primeiro grupo, o gênero é estudado no capítulo das flexões do substantivo. Adotam tal posição, dentre outros, os seguintes autores: Celso Pedro Luft, ${ }^{4}$ Gladstone Chaves de Melo, ${ }^{5}$ Mário

3. CÁMARA JR., J. Mattoso, Dicionário de F́lilologia e Gramática. 2. ed,. Rio de Janeiro, Ozon, 1964, verbete flexão.

4. LUFT, Celso Pedro. Moderna Gramática Brasileira. Porto Alegre, Globo, 1976, pp. 104-107.

5. MELO, Gladstone Chaves de. Gramática Fundamental da Língua Portuguesa. Rio de Janeiro, Acadêmica, 1968, p. 112. 
Pereira de Souza Lima, ${ }^{6}$ Domingos Paschoal Cegalla,7 Artur de Almeida Torres ${ }^{8}$ e Leodegário Amarante de Azevedo Filho. ${ }^{9} \mathrm{E}$ essa também a posição da NGB. ${ }^{10}$ Além disso, essa tem sido, via de regra, a prática mais comum no ensino do problema.

No segundo grupo, a diferença com relação aos autores do primeiro grupo, está no fato de que há uma declaração explícita de possibilidade de flexão. Convém transcrever a posição desses autores, para podermos discutir melhor a questão:

- Celso Cunha:

"Flexões dos substantivos — os substantivos podem variar em número, gênero e grau." 11

- Evanildo Bechara:

"Flexões do adjetivo - como o substantivo, o adjetivo pode variar em número, gênero e grau." 12

Apresentamos, em seguida, os dados de nossa pesquisa.

O quadro $n^{\circ} 2$ é, por um lado, uma extensão do quadro $n^{\circ} 1$, apresentado linhas atrás, pois contém os números relativos à pesquisa que empreendemos nos quatro textos do "corpus". Por outro lado, é também uma redução de parte do quadro $n^{0} 1$, no que se refere à distinção entre masculino e feminino. Tal distinção é, no momento, irrelevante.

6. LIMA, Mário Pereira de Souza. Gramática Expositiva da Lingua Portuguesa. São Paulo, Ed. Nacional, 1937, p. 306.

7. CEGALLA, Domingos Paschoal. Novissima Gramatica da Lingua Portuguesa. 20. ed., São Paulo, Ed. Nacional, 1979, p. 82.

8. TORRES, Artur de Almeida. Moderna Gramática Expositiva da Língua Portuguesa. 16. ed., São Paulo, Fundo de Cultura, 1964, p. 58.

9. AZEVEDO FILHO, Leodegário Amarante de. Gramática Básica da Lingua Portuguesa. Rio de Janeiro, Fundo de Cultura, 1968, p. 87.

10. NASCENTES, Antenor. Comentârio à Nomenclatura Gramatical Brasileira. Rio de Janeiro, Acadêmica, 1959, p. 13.

11. CUNHA, Celso Ferreira da. Gramática da Lingua Portuguesa. 5. ed,. Rio de Janeiro, FENAME, 1979, p. 191.

12. BECHARA, Evanildo. Moderna Gramática Portuguesa. 19. ed., São Paulo, Ed. Nacional, 1972, p. 89. 


\section{QUADRO 2}

\begin{tabular}{|c|c|c|c|c|c|}
\hline \multirow{3}{*}{ TEXTOS } & 一 SEXUADO & \multicolumn{3}{|c|}{ + SEXUADo } & \multirow{3}{*}{ TOTAL } \\
\hline & \multirow{2}{*}{ - FLEXão } & 一 DrST. & \multicolumn{2}{|c|}{ † DISTrNGÃO } & \\
\hline & & 一 flexão & 一 §lexão & + flexĩo & \\
\hline Técnico ......... & 937 & 46 & 05 & 12 & 1000 \\
\hline De reportagem ... & 856 & 47 & 30 & 67 & 1000 \\
\hline De memórias .... & 834 & 82 & 45 & 39 & 1000 \\
\hline De ficção ....... & 820 & 65 & 51 & 64 & 1000 \\
\hline TOTAL ......... & 3447 & 240 & 131 & 182 & 4000 \\
\hline
\end{tabular}

Como o que temos em mira é o problema da flexão, podemos extrair do quadro anterior ( $\left.\mathrm{n}^{\circ} 2\right)$ os dados que nos interessam e, a partir desses dados, elaborar um novo quadro $\left(n^{\circ} 3\right)$. Juntamos os números das três primeiras colunas em uma só (-flexão) e os comparamos com os números da $4^{\mathrm{a}}$ coluna ( + flexão).

\section{QUADRO 3}

\begin{tabular}{|l|c|c|c|c|c|c|}
\hline \multirow{2}{*}{ TEXTos } & \multicolumn{3}{|c|}{ NGMERos } & \multicolumn{3}{c|}{ PorcentaGEN } \\
\cline { 2 - 7 } & - flexão & +flexão & total & - flexão & + flexão & total \\
\hline \multirow{2}{*}{ Técnico } & 988 & 12 & 1000 & 98,8 & 1,2 & 100 \\
De reportagem & 933 & 67 & 1000 & 93,3 & 6,7 & 100 \\
De memórias & 961 & 39 & 1000 & 96,1 & 3,9 & 100 \\
De ficção & 936 & 64 & 1000 & 93,6 & 6,4 & 100 \\
TOTAL & 3818 & 182 & 4000 & 95,5 & 4,5 & 100 \\
\hline
\end{tabular}


Confrontando os dados da pesquisa com as posições das gramáticas, podemos fazer algumas considerações a respeito das relações entre gênero e flexão.

a) Os dados da pesquisa revelam que a grande maioria dos substantivos não recebe flexão de gênero $(95,5 \%)$.

b) Os autores do primeiro grupo estabelecem que o gênero dos substantivos está vinculado à flexão dos vocábulos.

c) Celso Cunha, um dos autores do segundo grupo, estabelece que os substantivos podem variar em gênero e apresentam a questão no capítulo referente à flexão dos vocábulos.

Evanildo Bechara, ao tratar do gênero do substantivo, não faz qualquer referência à flexão. ${ }^{13}$ Ao estudar o gênero do adjetivo, como verificamos na transcrição supra, estabelece que, "como o substantivo", o adjetivo pode variar em gênero. Esse item da gramática vem incluído no estudo das flexsões do adjetivo.

d) Considerando-se, porém, que a grande maioria dos substantivos não pode variar em gênero, a descrição coerente no caso seria, a nosso ver, a de que os substantivos da Língua Portuguesa normalmente não se flexionam quanto ao gênero. Uma descrição mais coerente e objetiva dos fatos seria, ainda, aquela que não fizesse qualquer alusão, a princípio, ao flexionamento das palavras. $\overrightarrow{\mathrm{E}}$ essa a posição de Evanildo Bechara e Said Ali, quando tratam do gênero do substantivo. ${ }^{14}$ Desse modo, a descrição e a teoria gramaticais estariam se apoiando naquilo que a língua apresenta de mais geral. Foi esse, aliás, o ponto de vista de Celso Cunha e Evanildo Bechara, ao tratarem da gradação dos advérbios.

Celso Cunha afirma, a propósito do assunto:

"Certos advérbios, principalmente os de modo, são suscetíveis de gradação". ${ }^{15}$

13. Id. ib., p. 83 .

14. ALI, M. Said. Gramuatica Secundaria da Língua Portuguesa. São Paulo, Melhoramentos, 1969, p. 33.

15. CUNHA, Celso. Op. cit., p. 154. 
De acordo com esse princípio, seria correto generalizar a questão e estabelecer que "os advérbios podem admitir gradação"? Embora correta em si, a afirmativa seria falha pelo fato de se apoiar em alguns casos apenas. A posição de Celso Cunha, de que "certos advérbios (...) são sucetíveis de gradação", corresponde, sem dúvida, à realidade dos fatos.

Evanildo Bechara, no capítulo sobre os advérbios, não faz, no início de sua exposição, qualquer referência à flexão dos advérbios. No final, afirma que "há certos advérbios, principalmente os de modo, que podem sofrer flexão gradual...".16 O autor partiu, sem dúvida, dos aspectos gerais da caracterização dessa classe de palavra, para chegar aos aspectos particulares.

$\overline{\mathrm{E}}$ essa a posição adotada por Amado Alonso e Henriquez Ureña, com relação ao gênero do substantivo espanhol, e que foi objetivo de considerações pormenorizadas na segunda parte da dissertação. Por ora, estamos apenas constatando que os autores não fazem, na caracterização do gênero do substantivo, qualquer referência à flexão das palavras. Depois de conceituado o gênero, em outros termos que não os flexionais, os autores afirmam:

"En unos pocos sustantivos, el género se manifiesta también como accidente gramatical, esto es, no sólo por la terminación del adjetivo acompañante, sino por dos formas distintas en el sustantivo mismo: niño niño, esposo esposa, pastor pastora, ciervo cierva, león leona, etc." 17

e) Da maneira como a questão foi colocada pelos autores do primeiro grupo, é possível concluir que todos os substantivos da Língua Portuguesa se flexionam para indicar o gênero. Já os autores do segundo grupo afirmam que os substantivos admitem, ou não, flexão de gênero. Mas como todos os substantivos da Língua Portuguesa estão enquadrados entre os masculinos ou os

16. BECHARA, Evanildo. Op. cit., p. 154.

17. ALONSO, Amado \& UREN̄A, Pedro Henriquez. Gramática Castellana. 22, ed., Buenos Aires, Losada, 1964, v. 1, p. 62. 
femininos e a quase totalidade não recebe flexão, parece-nos que a solução para o problema é a de desvincular o conceito de gênero do conceito de flexão. Há substantivos que recebem flexão de gênero e há os que não recebem. Mas todos, repetimos, são masculinos ou femininos.

Para termos uma idéia do caráter "sui generis" que apresenta o problema do gênero em português, basta compararmos com o mecanismo da flexão de número, que se descreve de maneira diferente A par da marca típica de plural, os substantivos apresentam uma desinência zero, característica do singular. Isso se dá, praticamente, com todos os substantivos comuns do português. Podemos, portanto, generalizar a questão e afirmar que os substantivos se flexionam para indicar o número. Consequientemente, um substantivo no singular ou no plural apresenta sempre flexão de número. E por isso que nomes como atlas, pires, lápis, oásis, ônibus e outros desse tipo, quando tomados isoladamente, não estão, a rigor, nem, no singular, nem no plural, uma vez que não se flexionam quanto ao número. ${ }^{18}$ Outras considerações a respeito da flexão de gênero em face da flexão de número foram apresentadas no Capítulo 4 da dissertação.

Com o gênero, como vimos, a colocação do problema é diferente. Os substantivos da Língua Portuguesa, em sua quase totalidade, classificam-se em masculinos ou femininos, independentemente de receber flexão. $O$ conceito de gênero não pode, portanto, estar subordinado ao conceito de flexão.

Como primeira conclusão do nosso trabalho, podemos estabelecer que os substantivos classificam-se em masculinos ou femininos, independentemente de admitirem flexão. $\overrightarrow{\mathrm{E}}$ preciso, portanto, desvincular o conceito de gênero do conceito de flexão.

18. «Mas, ao passo que a flexão de número é comum a todos os nomes (substantivos e adjetivos), salvo o grupo limitado de palavras graves que já terminaram em $/ \mathrm{s} /$, a flexão de gênero é privativa aos adjetivos de tema em -o e a uma certa porção de substantivos de qualquer terminação.» CÂMARA JR., J. Mattoso. História e Estrutura da Lingua Portuguesa. Rio de Janeiro, Padrão, 1976, p. 77-78. 


\section{GÊNERO E MORFOLOGIA}

A descrição do gênero do substantivo em português tem sido apresentada em nossas gramáticas, via de regra, como um dos itens da morfologia. A morfologia, por sua vez, tem sido conceituada por alguns autores nos seguintes termos:

Mário Pereira de Souza Lima:

"A parte da Gramática que estuda a constituição de palavras novas, as suas variações de forma e a sua classificação como parte do discurso denomina-se Morfologia (estudo das formas)". ${ }^{19}$

Gladstone Chaves de Melo:

"...é o estudo das palavras (ou formas), tomadas isoladamente (morphé em grego quer dizer 'forma')". ${ }^{20}$

Rocha Lima:

“... estudo das formas, sua estrutura e classificacão...".21

Evanildo Bechara:

“A Gramática estuda:

a) os sons da fala: Fonética e Fonêmica

b) as formas: Morfologia

c) as construções: Sintaxe

d) os sentidos e suas alterações: Semântica". ${ }^{22}$

Celso Pedro Luft:

"Parte da Gramática que se ocupa do sistema mórfico da língua, do aspecto formal das palavras". 23

19. LIMA, Souza, Op. cit., p. 282.

20. MELO, Gladstone Chaves de. Op. cit., p. 20.

21. LIMA, Rocha. Gramática Normativa da Lingua Portuguesa. 15. ed.; Rio de Janeiro, José Olympio, 1972, p. 6.

22. BECHARA, Evanildo. Op. cit., p. 25.

23. LUFT, Celso Pedro. Op. cit., p. 89. 
O texto da NGB estabelece:

"Trata a Morfologia das palavras:

a) quanto a sua estrutura e formação;

b) quanto a suas flexões; e

c) quanto a sua classificação" .24

Morfologia é, em síntese, segundo as citações, o estudo das palavras, consideradas sob o aspecto da forma.

Os autores apontados e a NGB incluem o estudo do gênero na morfologia. Consequientemente, o gênero deve ser encarado como um dos itens do estudo das formas das palavras.

São poucos os gramáticos brasileiros que não descrevem o gênero da maneira apresentada acima.

Celso Cunha não usa o termo morfologia e inclui o gênero no estudo da morfo-sintaxe. ${ }^{25}$

Said Ali não emprega também o termo em questão, preferindo em seu lugar lexiologia, que define como sendo o "estudo dos vocábulos". O autor esclarece que a lexiologia "não examina os vocábulos um por um, como o faz o dicionário. Divide-os em um pequeno número de grupos ou categorias e registra os fatos comuns e constantes e os fatos variáveis e excepcionais". ${ }^{26}$ O gênero é incluído por Said Ali na lexiologia.

O estudo do gênero como parte da morfologia apresenta algumas incoerências, conforme passamos a demonstrar.

Em primeiro lugar, como vimos em nossa pesquisa, 95,5\% dos substantivos não apresentam variação de forma pelo fato de estarem no masculino ou no feminino. Em outras palavras, o gênero não afeta a forma da grande maioria dos substantivos em português. Apenas 4,5\% dos substantivos sofrem variacãa de forma para indicar o gênero.

24. NASCENTES, Antenor. Op. cit., p. 10.

25. CUNHA, Celso. Op. cit., p. 186.

26. ALI, Said. Op. cit., p. 83. 
Em segundo lugar, conforme vimos no Capítulo 5 deste trabalho, quando discutimos as relações entre as categorias gramaticais e o gênero, numa frase como

- belo animal perdido no bosque parece cansado,

foi estabelecida uma relação formal entre animal e todas as palavras possuidoras da marca de gênero (com exceção de no, é claro, que se liga a bosque). Mostramos também que a questão pode ser representada da seguinte maneira:

o belo animal perdido no bosque parece cansado

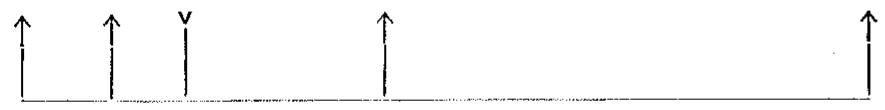

Através do exemplo, vemos que o substantivo animal̃ não sofre variação de forma, mas há quatro marcas específicas na frase para indicar que o gênero está presente.

$\overline{\mathrm{E}}$ preciso observar ainda que, mesmo nos casos em que $\mathrm{o}$ substantivo recebe a marca de flexão, o fenômeno do gênero não se restringe ao substantivo, mas atinge todos os determinantes flexionáveis com ele relacionados, como podemos verificar na frase seguinte, em que substituímos animal por loba;

a bela loba perdida no bosque parece cansada

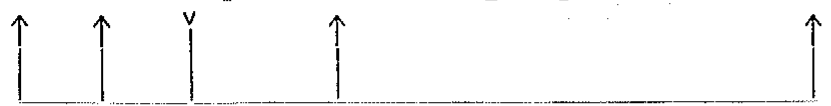

Como segunda conclusão deste trabalho, podemos afirmar que o gênero do substantivo em português não se circunscreve à morfologia, mas está relacionado também com o plano sintático da língua.

\section{CONCLUSÃO}

Retomemos aqui as duas conclusões parciais deste trabalho.

A primeira refere-se ao relacionamento entre o gênero do substantivo e a flexão: 
Os substantivos classificam-se en masculinos ou femininos, independentemente de admitirem flexão. $\overline{\mathrm{E}}$ preciso, portanto, desvincular o conceito do gênero do conceito de flexão.

A segunda conclusão refere-se ao relacionamento entre o gênero do substantivo e a morfologia:

O gênero do substantivo em português não se circunscreve à morfologia, mas está relacionado também com o plano sintático da língua.

A questão do gênero deve ser colocada num outro nível que não o puramente morfológico, como acabamos de demonstrar. Foi o que fizemos em nossa dissertação, quando definimos o gênero do substantivo como uma categoria morfo-sintática. Mas a nossa preocupação aqui foi apenas a de desvincular o conceito de gênero do de flexão e a de demonstrar que o gênero do substantivo extrapola uma perspectiva puramente morfológica. 